Tropical Journal of Pharmaceutical Research February 2019; 18 (2): 341-347

ISSN: $1596-5996$ (print); 1596-9827 (electronic)

(C) Pharmacotherapy Group, Faculty of Pharmacy, University of Benin, Benin City, 300001 Nigeria.

\title{
Cardioprotective effects of the total flavonoids of Polygonum cuspidatum Sieb. et Zucc. Root extract on experimental myocardial infarction in mice
}

\author{
Hai-Rong Yu, Yu-Lian Jiang, Dan-Dan Dong, Guo-Hong Wang* \\ Cardiovascular Center, Beijing Tongren Hospital, Capital Medical University, Beijing 100730, China \\ ${ }^{*}$ For correspondence: Email: guohongwang01@126.com; Tel: +86-010-58266699
}

Sent for review: 3 October 2018

Revised accepted: 18 January 2019

\begin{abstract}
Purpose: To study the cardioprotective effects of the total flavonoids from the roots of Polygonum cuspidatum Sieb. et Zucc. (FHZ) on experimental myocardial infarction in mice.

Methods: Ultrasonic-assisted extraction of FHZ was optimized by response surface methodology (RSM) to obtain a higher extraction yield. Myocardial infarction (MI) was established by ligation of the left anterior descending (LAD) branch of the coronary artery in mice. Cardiac troponin T (cTnT), creatine phosphokinase (CPK), lactate dehydrogenase (LDH), lipid peroxide (LPO), malondialdehyde (MDA) and superoxide dismutase (SOD) levels in the serum of mice were assessed by enzyme-linked immunosorbent assay. Furthermore, myocardial infarction size (MIS) was examined by Masson's Trichrome staining on heart tissues.

Results: Optimum extraction conditions of FHZ were as follows: an ethanol concentration of $69.03 \%$, a liquid-solid ratio of $27.14 \mathrm{~g} / \mathrm{mL}$ and an extraction time of $30.30 \mathrm{~min}$. The obtained extraction conditions were proven to be accurate and reliable. After treatment with $\mathrm{FHZ}$ for 3 and 7 days, the serum level of cTnT in MI mice decreased significantly. Also, the serum levels of CPK, LPO, MDA, and LDH were significantly decreased while SOD level increased in MI mice treated with FHZ. Furthermore, after treatment with FHZ for two weeks, the MIS of MI mice decreased $(p<0.01)$.

Conclusion: RSM is a useful tool to optimize the ultrasonic-assisted extraction conditions for FHZ. Furthermore, FHZ possesses significant cardioprotective effects on experimental myocardial infarction in mice and thus may find application in the clinical management of myocardial infarction.
\end{abstract}

Keywords: Polygonum cuspidatum, Flavonoids, Response surface methodology, Myocardial infarction, Cardioprotective

\begin{abstract}
This is an Open Access article that uses a funding model which does not charge readers or their institutions for access and distributed under the terms of the Creative Commons Attribution License (http://creativecommons.org/licenses/by/4.0) and the Budapest Open Access Initiative (http://www.budapestopenaccessinitiative.org/read), which permit unrestricted use, distribution, and reproduction in any medium, provided the original work is properly credited.
\end{abstract}

Tropical Journal of Pharmaceutical Research is indexed by Science Citation Index (SciSearch), Scopus, International Pharmaceutical Abstract, Chemical Abstracts, Embase, Index Copernicus, EBSCO, African Index Medicus, JournalSeek, Journal Citation Reports/Science Edition, Directory of Open Access Journals (DOAJ), African Journal Online, Bioline International, Open-J-Gate and Pharmacy Abstracts

\section{INTRODUCTION}

Acute myocardial infarction (AMI) resulting from coronary artery occlusion is a severe disease with a high mortality worldwide [1,2]. In China, more than 700,000 individuals die of AMI every year [3]. It was reported that AMI can lead to necrosis and initiate chronic cardiac dysfunction and pathological cardiac remodelling [4]. Although there are advances in the treatment of AMI, the irreversible loss of cardiomyocytes still leads to left ventricular remodeling and ischemic 
heart failure [5]. Therefore, it is vital to identify novel therapeutic drugs for the treatment of AMI. An increasing number of studies has found that traditional Chinese medicine (TCM) and its derived agents have remarkable effects in treating miscellaneous disorders, such as myocardial ischemia diseases [6,7]. Polygonum cuspidatum Sieb. et Zucc. (PSZ) is a herbaceous perennial plant belonging to the genus Polygonum [8]. Its dried root (Huzhang, in Chinese) has been widely used as a TCM in China for thousands of years for the treatment of conditions such as cough, hepatitis, jaundice, arthralgia and snake bites [9]. Studies have shown that Huzhang possesses favorable therapeutic effects on hyperlipidemia, hypertension, and cardiovascular and neurodegenerative diseases [10]. Huzhang contains abundant active constituents such as flavonoids, quinones, stilbenes, coumarins and lignans. However, not much is known about the pharmacological effects of flavonoids extracted from Huzhang (FHZ).

The present study was designed to optimize the ultrasonic-assisted extraction conditions of the total flavonoids from the roots of Polygonum cuspidatum Sieb. et Zucc. using RSM and to investigate the cardioprotective effects of $\mathrm{FHZ}$ in mice with experimental myocardial infarction.

\section{EXPERIMENTAL}

\section{Chemicals and reagents}

Rutin standard was purchased from the National Institute for Food and Drug Control (Beijing, China); Cardiac troponin $\mathrm{T}$ (cTnT), creatine phosphokinase (CPK), lactate dehydrogenase $(\mathrm{LDH})$, lipid peroxide (LPO), malondialdehyde (MDA), and superoxide dismutase (SOD) enzyme-linked immunosorbent assay (ELISA) kits were obtained from Nanjing Jiancheng Bioengineering Institute (Nanjing, China). Masson's Trichrome stain kit was obtained from Solarbio Life Science (Beijing, China). Other chemicals and reagents were of analytical grade.

\section{Extraction of flavonoids from Huzhang (FHZ)}

Dried Huzhang was collected from the Anguo Chinese herbal medicine market (Anguo, China) and was authenticated by the Pharmacognosy Department in Beijing Tongren Hospital (Beijing, China). A voucher specimen (SH1007-3) has been stored in the herbarium of Beijing Tongren Hospital (Beijing, China). The dried Huzhang was powdered and sifted through a standard sieve (internal diameter $420 \mu \mathrm{m}$ ). The powder was extracted by ultrasound using a KQ-5200 ultrasonic extractor (Kunshan Ultrasonic Instrument Co., Ltd, Kunshan, China) with extraction parameters (Table 1). The total flavonoid content was determined after extraction according to a modified method [11] using rutin as a standard.

Table 1: Factors and levels for Box-behnken design (BBD)

\begin{tabular}{lccc}
\hline Factor & \multicolumn{3}{c}{ Levels } \\
\hline Ethanol concentration & 60 & 70 & 80 \\
$(\%)$ & 20 & 30 & 40 \\
Liquid-solid ratio $(\mathrm{g} / \mathrm{mL})$ & 25 & 35 & 45 \\
Extraction time $(\mathrm{min})$ &
\end{tabular}

\section{Experimental design}

The effects of the the ethanol concentration $(A)$, liquid-solid ratio $(B)$, and extraction time $(C)$ on the extraction yield were investigated. Optimization of the ultrasound extraction of $\mathrm{FHZ}$ was carried out using response surface methodology (RSM) [12] and a three-factor, three-level Box-Behnken design (BBD) consisting of 17 experimental runs was empolyed (Table 2). The FHZ content (\%) was calculated as the response value of the RSM.

\section{Animals}

Male C57BL/6 adult mice (8 weeks old, $20 \pm 2 \mathrm{~g}$ ) were obtained from Shanghai Animal Administration Center (Shanghai, China). The mice were free access to food and water, and were housed in a standard enviroment. All animal experiments were authorized by the Ethics Committee of Beijing Tongren Hospital, Beijing, China (approval no. AM2017-17) and carried out according to the guidelines of "The Guide for the Care and Use of Laboratory Animals" (NIH Publication no. 85-23, revised 1996) [13].

\section{Infarct model and groups}

The mice were anesthetized intraperitoneally with chloral hydrate and the myocardial infarction (MI) model was established by permanent ligation of the left anterior descending (LAD) branch of the coronary artery [14]. Negative control mice underwent the same surgery without LAD ligation. After the MI model was established, the mice were treated with different doses of $\mathrm{FHZ}$ $(120,240$, and $480 \mathrm{mg} / \mathrm{kg})$ by intragastric administration once a day for 2 weeks.

\section{cTnT level in serum of mice}

On days 3 and 7 after $\mathrm{FHZ}$ administration, blood was collected from the tail vein of mice and the 
serum samples were prepared. The level of cTnT in the serum of mice was assayed using ELISA kit according to the manufacturer's instructions.

\section{CPK, LDH, LPO, MDA and SOD levels in the serum of mice}

After 2 weeks of administration, the mice were killed by picking up the eyeball and the blood was collected. Serum was prepared by centrifugation and CPK, LDH, LPO, MDA, and SOD levels were evaluated by ELISA.

\section{Myocardial infarction size}

The hearts of the mice were removed and heart tissues were used to measure the myocardial infarction size (MIS) by Masson's Trichrome staining 2 weeks after $\mathrm{MI}$, as previously described [15]. The areas of infarction and area of the whole left ventricle (LV) were assessed by computer morphometry using Image $\mathrm{J}$ software (NIH Image, Bethesda, MD, USA). MIS was calculated using Eq 1.

$\operatorname{MIS}(\%)=\left(A_{1} / A_{2}\right) 100$

where $A 1$ is the area of infarction, and $A 2$ is the area of whole LV

\section{Statistical analysis}

The data are presented as mean \pm standard deviation (SD). Design Expert (version 8.0.6.1, Stat-Ease, Inc., USA) and SPSS software (version 19.0, IBM Corporation, NY, USA) were used to analyze the data. One-way analysis of variance (ANOVA) was used to analyze the difference between different groups, and $p<0.05$ was considered statistically significant.

\section{RESULTS}

\section{Model fitting and RSM data}

In the present study, a BBD with three factors and three levels was used. The experimental design of the BBD and results of 17 experiments are shown in Table 2. The content of FHZ ranged from 4.76 to $7.59 \%$. The content of $\mathrm{FHZ}(\mathrm{Y})$ influenced by the three factors was fitted using a second-order polynomial equation as in $\mathrm{Eq} 2$.

$Y=-46.96+1.67 A-0.15 B-0.073 C+0.0052$ $A B+0.0025 A C+0.0036 B C-0.014 A^{2}-$ $0.0057 B^{2}-0.0032 C^{2}$

where $Y$ represents the content of $F H Z$, and $A$, $B$, and $C$ represent the ethanol concentration, liquid-solid ratio, and extraction time, respectively.

The ANOVA for the quadratic model is shown in Table 3. The results show that the model is of high significance with a very low $p$-value $(<0.0001)$. The determination coefficient value $\left(R^{2}\right)$ of 0.9834 indicated a significant correlation between the predicted values and actual values. Lack of fit was not significant $(p=0.1395)$, indicating that variation can be predicted by the quadratic model. In this model, the linear parameter $\mathrm{C}$ and all the interaction and quadratic parameters were significant $(p<0.05)$ for $\mathrm{FHZ}$ content. The interactions between the parameters were also shown in the 3D response surface plot of RSM (Figure 1).

Table 2: The results of the BBD experiments

\begin{tabular}{lcccc}
\hline Run & $\mathbf{A}(\%)$ & $\mathbf{B}(\mathbf{m L} / \mathbf{g})$ & $\mathbf{C}(\mathbf{m i n})$ & Content $\mathbf{( \% )}$ \\
\hline 1 & 70.00 & 40.00 & 25.00 & 6.37 \\
2 & 70.00 & 20.00 & 45.00 & 6.11 \\
3 & 70.00 & 40.00 & 45.00 & 6.68 \\
4 & 80.00 & 20.00 & 35.00 & 5.32 \\
5 & 60.00 & 20.00 & 35.00 & 6.09 \\
6 & 70.00 & 30.00 & 35.00 & 7.28 \\
7 & 70.00 & 30.00 & 35.00 & 7.53 \\
8 & 60.00 & 40.00 & 35.00 & 4.76 \\
9 & 80.00 & 30.00 & 45.00 & 5.77 \\
10 & 60.00 & 30.00 & 45.00 & 5.53 \\
11 & 70.00 & 30.00 & 35.00 & 7.59 \\
12 & 80.00 & 40.00 & 35.00 & 6.05 \\
13 & 60.00 & 30.00 & 25.00 & 6.34 \\
14 & 70.00 & 30.00 & 35.00 & 7.56 \\
15 & 70.00 & 20.00 & 25.00 & 7.23 \\
16 & 70.00 & 30.00 & 35.00 & 7.52 \\
17 & 80.00 & 30.00 & 25.00 & 5.58 \\
\hline
\end{tabular}


Table 3: ANOVA results for BBD

\begin{tabular}{|c|c|c|c|c|c|}
\hline Source & Sum of Squares & df & Mean Square & F -Value & p-value \\
\hline Model & 12.60 & 9 & 1.40 & 45.98 & $<0.0001$ \\
\hline A & 0.000 & 1 & 0.000 & 0.000 & 1.0000 \\
\hline B & 0.099 & 1 & 0.099 & 3.25 & 0.1143 \\
\hline C & 0.26 & 1 & 0.26 & 8.40 & 0.0231 \\
\hline$A B$ & 1.06 & 1 & 1.06 & 34.86 & 0.0006 \\
\hline$A C$ & 0.25 & 1 & 0.25 & 8.21 & 0.0241 \\
\hline$B C$ & 0.51 & 1 & 0.51 & 16.80 & 0.0046 \\
\hline$A^{2}$ & 7.87 & 1 & 7.87 & 258.43 & $<0.0001$ \\
\hline $\mathrm{B}^{2}$ & 1.39 & 1 & 1.39 & 45.62 & 0.0003 \\
\hline$C^{2}$ & 0.44 & 1 & 0.44 & 14.55 & 0.0066 \\
\hline Residual & 0.21 & 7 & 0.030 & & \\
\hline Lack of Fit & 0.15 & 3 & 0.051 & 3.30 & 0.1395 \\
\hline Pure Error & 0.061 & 4 & 0.015 & & \\
\hline Cor Total & 12.81 & 16 & & & \\
\hline C.V.\% & 2.71 & & & & \\
\hline $\mathrm{R}^{2}$ & 0.9834 & & & & \\
\hline$R^{2}$ Adj & 0.9620 & & & & \\
\hline $\mathrm{R}^{2}$ Pred & 0.8030 & & & & \\
\hline $\begin{array}{l}\text { Adequate } \\
\text { Precision }\end{array}$ & 19.187 & & & & \\
\hline
\end{tabular}

\section{Optimized and verified results}

The optimum extraction conditions obtained by Design Expert software were as follows: an ethanol concentration of $69.03 \%$, a liquid-solid ratio of $27.14 \mathrm{~g} / \mathrm{mL}$, and an extraction time of $30.30 \mathrm{~min}$. Verification experiments using these conditions showed that experimental content of $\mathrm{FHZ}(7.61 \%)$ was consistent with the predicted value $(7.55 \%)$ indicating that the obtained extraction conditions in the present study were accurate and reliable.

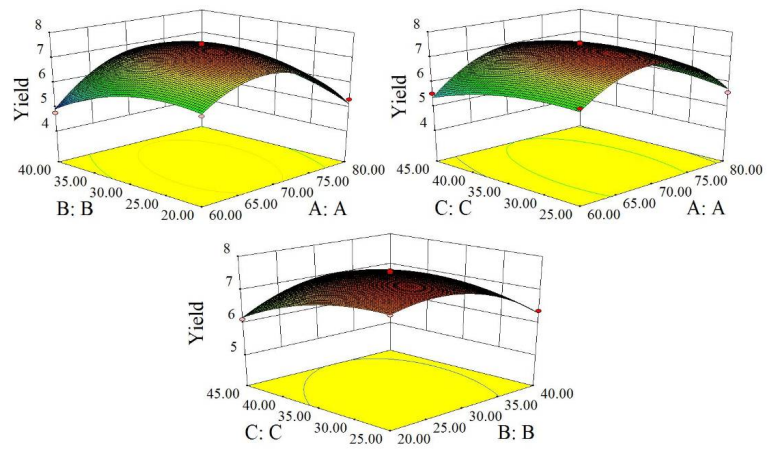

Figure 1: 3D response surface plot

\section{Serum cTnT levels in mice}

As shown in Figure 2, the cTnt level in the negative control group was significantly increased $(p<0.01)$, indicating that the MI model was successfully established. Interestingly, after treatment with $\mathrm{FHZ}(120,240$, and $480 \mathrm{mg} / \mathrm{kg})$ for 3 and 7 days, the cTnT level in the serum of MI mice was significantly decreased.

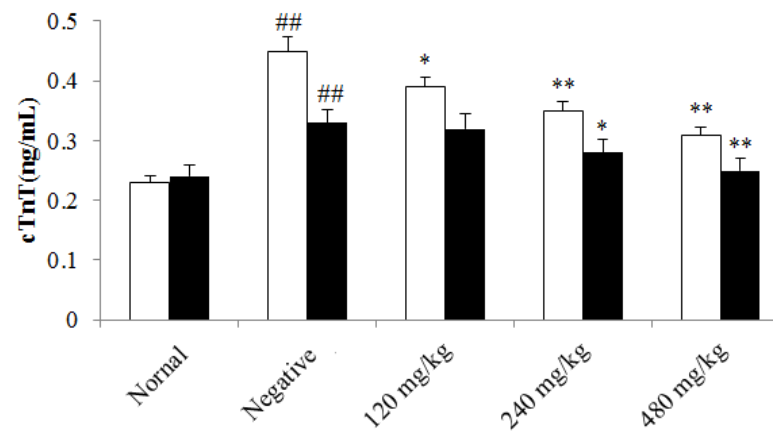

Figure 2: Serum cTnT levels in mice. Key: $\square=$ levels on day 3 , $=$ the levels on day 7; \#\#p < 0.01, compared with normal control; ${ }^{\star} p<0.05,{ }^{\star *} p<0.01$, compared with negative control

\section{CPK, LDH, LPO, MDA and SOD levels in mouse serum}

The serum levels of CPK, LDH, LPO, MDA, and SOD in the mice were evaluated by ELISA, and the results are shown in Figure 3 . The levels of CPK, LDH, LPO, and MDA in negative control group were obviously increased $(p<0.01)$, while the level of SOD was decreased $(p<0.01)$, compared with those in normal control group.

After $\mathrm{FHZ}$ adiministration for two weeks, CPK, LPO, MDA levels were significantly decreased at all the tested doses $(p<0.05, p<0.01$ and $p<$ 0.01 , respectively), while the LDH was decreased at the doses of 240 and $480 \mathrm{mg} / \mathrm{mL}(p$ $<0.05$ and $p<0.01$, respectively). FHZ also significantly and dose-dependently increased the levels of SOD $(p<0.01)$ in the serum of mice, compared with those in mice in negative control group. 


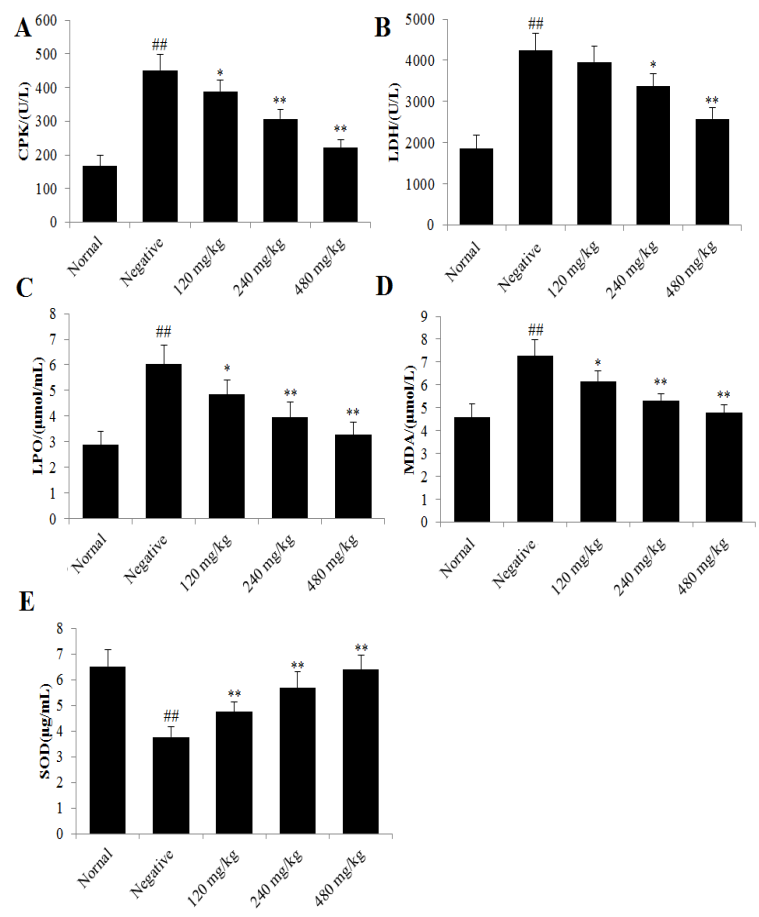

Figure 3: CPK, LDH, LPO, MDA, and SOD levels in the serum of mice. A - E represent CPK, LDH, LPO, MDA, and SOD levels, respectively. \#\#p < 0.01, compared with normal control; ${ }^{*} p<0.05,{ }^{* *} p<0.01$, compared with the negative control group

\section{MIS levels}

Myocardial infarction was obvious in the negative control group and MIS was larger $(p<0.01)$ than that in normal control (Figure 4). Treatment with $\mathrm{FHZ}(120,240$, and $480 \mathrm{mg} / \mathrm{kg})$ for two weeks significantly decreased the MIS $(p<0.01)$ in MI model mice.

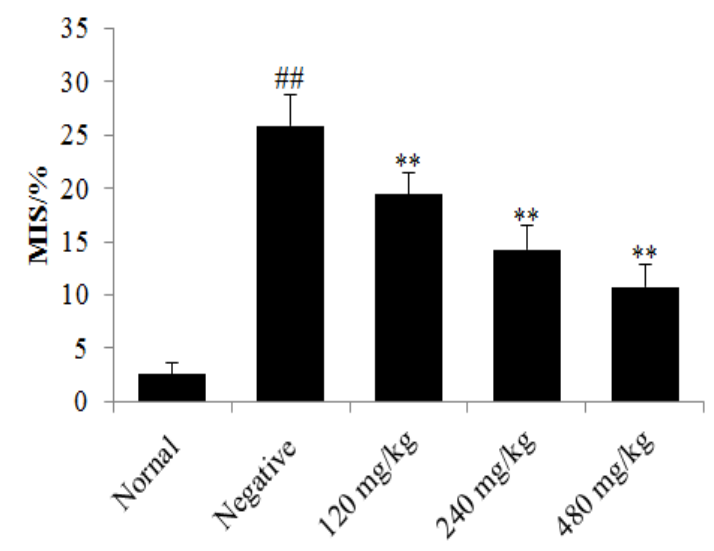

Figure 4: MIS of mice in different groups. \#\# $<0.01$, compared with normal control; ${ }^{* \star} p<0.01$, compared with negative control

\section{DISCUSSION}

Flavonoids are known bioactive compounds, and many studies have focused on the extraction optimization of flavonoids and their pharmacological activities [16]. Ultrasoundassisted extraction (UAE) is a more effective technique than other extraction methods to extract flavonoid compounds from plant sources $[17,18]$. Moreover, RSM is usually applied to investigate the effects of UAE parameters on the extraction of flavonoids from herbs. It is widely used to study the relationships between the response value and designed variables [19].

In the present study, the extraction parameters of total flavonoids from Huzhang were optimized by employing RSM, and the results indicated that the obtained extraction conditions by RSM were accurate and reliable. CTnT is a regulatory contractile protein, and it is found in blood when the myocardial cells are damaged. Therefore, it is usually used as a sensitive and specific marker for myocardial cell damage [20]. Myocardial necrosis caused by local ischemia and hypoxia is one of the main causes of Ml-induced heart failure. Reducing MIS and improving myocardial function have become the main therapeutic targets of drugs against $\mathrm{MI}$ [21]. In the present study, FHZ treatment decreased the serum cTnT level and MIS value in the MI mice, indicating that $\mathrm{FHZ}$ had therapeutic effects on MI.

Myocardial ischemia often leads to oxidative stress and can be evaluated by using the LPO, MDA, and SOD levels, and some myocardial enzymes including CPK and LDH were often used as indicators of myocardial injury evaluation $[7,22]$. The results showed that $F H Z$ decreased the serum levels of CPK, LPO, MDA, and LDH, and increased the SOD level in MI mice, demonstrating that $\mathrm{FHZ}$ protected against $\mathrm{MI}$ by attenuating oxidative stress and decreasing the levels of myocardial enzymes.

\section{CONCLUSION}

RSM is a useful tool for the optimization of extraction conditions for $\mathrm{FHZ}$ by ultrasonicassisted extraction. The results also indicate that $\mathrm{FHZ}$ possesses significant cardioprotective effects in experimental myocardial infarction in mice. Thus, it has the potential to be developed into cardioprotective drugs for the treatment of Ml.

\section{DECLARATIONS}

\section{Acknowledgement}

This study was supported by Zhejiang Medical and Health Science and Technology Project (no. 2016KYA197). 


\section{Conflict of interest}

No conflict of interest is associated with this work.

\section{Contribution of authors}

We declare that this work was done by the authors named in this article and all liabilities pertaining to claims relating to the content of this article will be borne by the authors. Guo-Hong Wang conceived and designed the study. HaiRong $\mathrm{Yu}$ and $\mathrm{Yu}$-Lian Jiang collected and analyzed the data. Yu-Lian Jiang and Dan-Dan Dong wrote the manuscript. All authors read and approved the manuscript for publication.

\section{REFERENCES}

1. Liu L, Jin X, Hu CF, Zhang YP, Zhou Z, Li R, Shen CX. Amphiregulin enhances cardiac fibrosis and aggravates cardiac dysfunction in mice with experimental myocardial infarction partly through activating EGFRdependent pathway. Basic Res Cardiol 2018; 113(2): 12.

2. Clark JE, Dudler T, Marber MS, Schwaeble W. Cardioprotection by an anti-MASP-2 antibody in a murine model of myocardial infarction. Open Heart 2018; 5(1): e000652.

3. Yu B, Wang W. Cardioprotective effects of morroniside in rats following acute myocardial Infarction. Inflammation 2018; 41(2): 432-436

4. Gao LR, Chen $Y$, Zhang NK, Yang XL, Liu HL, Wang ZG, Yan $X Y$, Wang $Y$, Zhu ZM, Li TC, et al. Intracoronary infusion of Wharton's jelly-derived mesenchymal stem cells in acute myocardial infarction: double-blind, randomized controlled trial. BMC Med 2015; 13: 162.

5. Yu B, Zhang G, An Y, Wang W. Morroniside on antiinflammation activities in rats following acute myocardial infarction. Korean J Physiol Pharmacol 2018; 22(1): 1721.

6. Peng $W$, Shen $H$, Lin B, Han $P, L i C H$, Zhang $Q Y, Y e B Z$, Rahman K, Xin HL, Qin LP, Han T. Docking study and antiosteoporosis effects of a dibenzylbutane lignan isolated from Litsea cubeba targeting Cathepsin $K$ and MEK1. Med Chem Res 2018; 27: 2062-2070.

7. Li F, Fan XX, Chu C, Zhang Y, Kou JP, Yu BY. A strategy for optimizing the combination of active components based on Chinese medicinal formula Sheng-Mai-San for myocardial ischemia. Cell Physiol Biochem 2018; 45(4): 1455-1471.

8. Wang C, Yang $S$, Lu H, You H, Ni M, Shan W, Lin T, Gao $X$, Chen $H$, Zhou $Q$, et al. A natural product from Polygonum cuspidatum Sieb. Et Zucc. Promotes TatDependent HIV latency reversal through triggering $P$ TEFb's release from 7SK snRNP. PLoS One 2015; 10(11): e0142739.
9. Zhang H, Li C, Kwok ST, Zhang QW, Chan SW. A review of the pharmacological effects of the dried root of Polygonum cuspidatum (Hu Zhang) and its constituents. Evid Based Complement Alternat Med 2013; 2013: 208349.

10. Jia YM, Wang JM, Cui Y. Research progress in pharmacological actions of rhizomn Polygoni Cuspidati based on stilbene compounds as main bioactive component. Chin J Exp TCM 2011; 17: 263-269.

11. Yu J, Lou $Q$, Zheng $X$, Cui Z, Fu J. Sequential combination of microwave- and ultrasound-assisted extraction of total flavonoids from Osmanthus fragrans Lour. flowers. Molecules 2017; 22(12): pii: E2216.

12. Huang HS, Liaw ET. Extraction optimization of flavonoids from Hypericum formosanum and Matrix Metalloproteinase-1 inhibitory activity. Molecules 2017; 22(12): pii: E2172.

13. "Principles of Laboratory Animal Care" (NIH publication no. 85-23, revised 1985). Available from: http://grants 1.nih.gov/grants/olaw/references/phspol.htm

14. Kompa AR, Lu J, Weller TJ, Kelly DJ, Krum H, von Lueder TG, Wang BH. Angiotensin receptor neprilysin inhibition provides superior cardioprotection compared to angiotensin converting enzyme inhibition after experimental myocardial infarction. Int J Cardiol 2018; 258: 192-198.

15. Hofmann U, Knorr S, Vogel B, Weirather J, Frey A, Ertl G, Frantz S. Interleukin-13 deficiency aggravates healing and remodeling in male mice after experimental myocardial infarction. Circ Heart Fail 2014; 7(5): 822830.

16. Ko MJ, Kwon HL, Chung MS. Pilot-scale subcritical water extraction of flavonoids from satsuma mandarin (Citrus unshiu Markovich) peel. Innov. Food Sci Emerg 2016; 38: 175-181.

17. Liu $Y$, Wang H, Cai X. Optimization of the extraction of total flavonoids from Scutellaria baicalensis Georgi using the response surface methodology. J Food Sci Technol 2015; 52(4): 2336-2343.

18. Ramić M, Vidović S, Zeković Z, Vladić J, Cvejin A, Pavlić $B$. Modeling and optimization of ultrasound-assisted extraction of polyphenolic compounds from Aronia melanocarpa by-products from filter-tea factory. Ultrason Sonochem 2015; 23: 360-368.

19. Ballard TS, Mallikarjunan $P$, Zhou K, O'Keefe SF. Optimizing the extraction of phenolic antioxidants from peanut skins using response surface methodology. J Agric Food Chem 2009; 57(8): 3064-3072.

20. Ambavane A, Lindahl B, Giannitsis E, Roiz J, Mendivil J, Frankenstein L, Body R, Christ M, Bingisser R, Alquezar $A$, et al. Correction: Economic evaluation of the onehour rule-out and rule-in algorithm for acute myocardial infarction using the high-sensitivity cardiac troponin $T$ assay in the emergency department. PLoS One 2018; 13(1): e0191348.

21. Wu F, Yu B, Zhang $X$, Zhang Y. Cardioprotective effect of Notch signaling on the development of myocardial 
infarction complicated by diabetes mellitus. Exp Ther Med 2017; 14(4): 3447-3454.

22. Wang $N$, Min $X$, Li $D$, He $P$, Zhao $L$. Geranylgeranylacetone protects against myocardial ischemia and reperfusion injury by inhibiting highmobility group box 1 protein in rats. Mol Med Rep 2012; 5(2): 521-524. 